\title{
El proceso de madurez del personaje fílmico. El caso de Lucía en Silencio roto, de Montxo Armendáriz
}

\section{The process of maturity of the filmic character. The case of Lucia in Silencio roto, by Montxo Armendáriz}

\author{
Ander Goikoetxea Pérez \\ Universidad del País Vasco / Euskal Herriko Unibertsitatea, España \\ ander.goikoetxea@ehu.eus
}

\section{Resumen:}

El héroe de las mil caras (Joseph Campbell, 1949) es considerada una referencia obligada para los guionistas que vayan a narrar la historia de un largometraje. Este estudio pretende corroborar que a menudo el cine contemporáneo sigue los patrones descubiertos por el mitólogo estadounidense. Mediante el análisis de Lucía en Silencio roto (Armendáriz, 2001) se pretende comprender las claves que exponen el proceso iniciático del personaje fílmico con el objetivo de saber sobre la idoneidad de la aplicación de dichos patrones remotos en las narrativas del cine de principios de milenio. El enfoque escogido por el director es idóneo para transmitir la evolución que desea mostrar, ya que este tipo de focalización ayuda a la identificación del espectador.

\section{Abstract:}

The hero with a thousand faces (Joseph Campbell, 1949) is considered an obligatory reference for writers who will write the story of a feature film. This study aims to corroborate that contemporary cinema often follows the patterns discovered by the American mythologist. Through the analysis of Lucía in Silencio roto (Armendáriz, 2001), it aims to understand the keys that expose the initiatory process of the film character with the aim of knowing about the suitability of the application of these remote patterns in the of cinema of the beginning of the millennium. The approach chosen by the director is ideal to transmit the evolution he wants to show, since this type of focalization helps to identify the viewer.

Palabras clave: Narrativa audiovisual; personaje fílmico; ficción; héroe; evolución; Joseph Campbell.

Keywords: Audiovisual narrative; film character; fiction; hero; evolution; Joseph Campbell. 


\section{Introducción}

Vivimos en un mundo muy complejo en el que cada individuo recibe muchos más estímulos y mensajes mediante dos horas frente al televisor que ningún otro de hace 100 años durante todo un mes (Aguilar Carrasco, 2010, p. 71). En este sentido, cabe pensar que una sociedad mucho más compleja cuenta historias mucho más enmarañadas. O lo que es lo mismo, partiendo de que el cine es la expresión de la sociedad contemporánea, las historias que se relatan en él deberían ser mucho más complejas que las antiguas leyendas populares. Pero lo cierto es que todavía podemos observar que a día de hoy siguen vigentes las teorías narratológicas de Aristóteles. Así pues, las historias que más fascinan son aquellas que se estructuran en los clásicos tres actos: planteamiento, nudo y desenlace. De esa manera, las acciones van originándose una tras otra bajo un hilo conductor. Es por ello que los relatos bien construidos no comienzan por cualquier punto ni terminan en otro sin determinar; salvo en excepciones, deben atenerse a dichas normas para su éxito.

Christopher Vogler (2002), asesor guionista de Hollywood ${ }^{1}$, afirma que en el cine actual se utilizan las antiguas estructuras narrativas descubiertas por Joseph Campbell. El mitólogo, escritor y profesor estadounidense estableció en 1949 un patrón narrativo que encontró en las historias y leyendas populares de todo el mundo. De esa manera, Campbell (1990) analizó los mitos, pasajes religiosos, leyendas, tradiciones y sueños personales de diferentes civilizaciones culturales y épocas, descubriendo que a lo largo de la historia, y en todo el mundo, hay leyendas similares. Reconoce que hay diferencias entre las numerosas mitologías y leyendas religiosas, pero insiste en comprender las semejanzas, pues así se entenderá que las diferencias son mucho menos grandes de lo que se presupone. El mitólogo utilizó como método de aproximación los principios del psicoanálisis ${ }^{2}$ para presentar las mitologías como expresión de la mente humana, con el objetivo

\footnotetext{
1 Ha trabajado como asesor en películas como El Rey León (Rob Minkoff \& Roger Allers, 1994), Pulp Fiction (Quentin Tarantino,1995), The Full Monty (Peter Cattaneo, 1997), Star Wars o Titanic (James Cameron, 1998).

2 Especialmente el estudio de los símbolos y arquetipos sugeridos por Carl Gustav Jung, en el que hace referencia a modelos de personalidad que se repiten desde hace siglos. Según Jung, existe un inconsciente colectivo, parecido al individual: "Los cuentos de hadas y los mitos son como sueños compartidos por toda la cultura, que emanan del inconsciente colectivo" (Vogler, 2002, p. $60)$.
} 
de representar y resolver algunos dilemas de la especie:

Sea que escuchemos con divertida indiferencia el sortilegio fantástico de un médico brujo de ojos enrojecidos del Congo, o que leamos con refinado embeleso las pálidas traducciones de las estrofas del místico Lao-Tse, o que tratemos de romper, una y otra vez, la dura cáscara de un argumento de Santo Tomás, o que captemos repentinamente el brillante significado de un extraño cuento de hadas esquimal, encontraremos siempre la misma historia de forma variable y sin embargo maravillosamente constante, junto con una incitante y persistente sugestión de que nos queda por experimentar algo más que lo que podrá ser nunca sabido o contado. (Campbell, 1990, p. 10)

El héroe de las mil caras es considerada una referencia obligada tanto para los guionistas que van a redactar la historia de una película como para los realizadores. Como bien apunta Vogler (2002, p. 11), este estudio confirma que a menudo el cine de hoy en día sigue los patrones descubiertos por el mitólogo estadounidense.

En la primera parte, llamada El viaje del héroe, Campbell dispone la trayectoria personal del héroe, en la que el neófito tiene que superar diversas pruebas para obtener el pleno conocimiento. A esa trayectoria le llama el monomito3 que, en definitiva, es el viaje que uno hace a través del inconsciente del héroe en el que exploramos nuestro propio conocimiento plasmándose en las hazañas de los héroes. De ese modo, diferentes autores han encontrado los patrones de dicho viaje en los héroes de múltiples largometrajes. Marzabal (2004) analiza el monomito de Homer Welles en Las normas de la casa de la sidra (Lasse Hallström, 1999), donde un adolescente siente la necesidad de abandonar el mundo que le es conocido para adentrarse en otro enigmático con la promesa de experiencias más enriquecedoras. Henderson (2005) explica cómo Luke Skywalker, de la saga Star Wars, pasa de la ignorancia al conocimiento a través de la experiencia. En este caso, son dos los motivos del viaje: el interno, el deseo de saber más sobre su padre; y el externo, la llegada de R2D2 y C-3PO con un mensaje de una princesa en peligro que necesita ser rescatada. No obstante, el proceso iniciático del héroe además de encontrarlo en el cine, podemos hallarlo

3 Campbell toma la palabra 'monomito' de James Joyce para representar el camino común de la aventura mitológica del héroe mediante una fórmula simbolizada en los ritos de iniciación: separación-iniciación-retorno. 
en la literatura, en el anime japonés, en los videojuegos e, incluso, en el turismo ${ }^{4}$. En la misma línea, Seger (1994) incide en la importancia de las historias universales, puesto que ayuda a identificarnos con los héroes. Según la guionista, hay dos tipos de historias universales: las historias de búsquedas y las historias de héroes. Son historias comunes que tienen como raíz nuestra existencia universal. Son mitos y su poder radica en historias vividas por todos nosotros:

Todos nosotros tenemos experiencias semejantes. Compartimos el viaje de la vida, del crecimiento del desarrollo y transformación. Vivimos siempre las mismas historias, ya sea la búsqueda de la perfecta compañera, el regreso al hogar, el encuentro de la plenitud, la persecución de un ideal, la realización de un sueño, o la caza de un preciado tesoro. Sea cual fuere nuestra cultura, existen historias universales que forman la base de todas nuestras historias particulares. Las circunstancias pueden ser diferentes, los giros y quiebros que crean el suspense pueden variar de una cultura a otra, pero en todas ellas encontramos siempre la misma historia, bosquejada a partir de las mismas experiencias. (Seger, 1994, p. 144)

\section{Objetivos y metodología}

Este artículo se presenta desde una investigación cualitativa y en su desarrollo se han utilizado las bases teóricas de los arquetipos planteados por Campbell. Mediante el análisis de Lucía en Silencio roto (Armendáriz, 2001) se pretende dar con las claves que exponen la iniciación de ese personaje fílmico. De igual manera, se examinarán las diferentes funciones que desempeñan los personajes en el relato del film. Todo eso con el fin de entender por qué el director se ha decantado por esa concreta estructura narrativa y qué es lo que ha buscado con ella. En definitiva, se procura saber la idoneidad de la aplicación de los patrones establecidos por Campbell en el cine contemporáneo.

El concepto 'arquetipo' es una herramienta indispensable para comprender la función o el propósito de los personajes que participan en cualquier historia (Vogler, 2002). El asesor guionista afirma que hay dos cuestiones que son fundamentales para el escritor cuando se trata de identificar la naturaleza de un

4 Pampín aborda el viaje turístico contemporáneo a través de una interpretación mítica basada en El viaje del héroe. 
arquetipo: en primer lugar, hay que determinar cuál es la función psicológica del personaje, qué personalidad representa; y en segundo lugar, hay que establecer su función dramática en la historia.

Mediante su identificación y análisis se quiere investigar la representación del maquis, es decir, el mensaje de la película. Conocedores de que algunos autores ya han analizado la película, este trabajo pretende abordar Silencio roto desde un nuevo enfoque, como complemento de las anteriores investigaciones. Para ello se han identificado los recursos narrativos y estéticos, teniendo en cuenta la singularidad del cine. Este estudio parte de un análisis formal de los personajes principales del film puesto que, tal y como afirma Pérez Rufí, analizar el personaje mediante el rol que desempeña, posibilitan el reconocimiento de la función y la actividad del personaje o de sus posiciones morales, positiva en el caso del héroe y, negativa en la del antagonista (2016).

El valor más importante del cine es que su relato conmueve al espectador: despierta sus sentimientos tocando su fibra sensible y genera pensamiento. Para ello es necesario planificar, sistematizar e integrarse con la imagen y el sonido, lo que permite influir en el espectador. En los siguientes puntos trataremos de aproximarnos al relato de Silencio Roto, a su estructura y su sentido, junto con los códigos audiovisuales.

Los conceptos de narratología se adquieren determinando y concretando el sentido de cada uno de los elementos de la comunicación narrativa, a partir de los elementos necesarios para definir el relato (García Landa, 1998). En una primera aproximación podemos tener muy pocos conceptos y definirlos de forma global. Tal y como García Landa apunta, esto puede ser suficiente en estudios no específicamente narratológicos si la estructura del texto analizado no es muy compleja. Pero los conceptos simples e intuitivos no siempre son suficientes: su inmediatez conlleva inexactitud y se convierte en contrapartida de la capacidad explicativa. En la medida en que se dice que el relato es una representación de la realidad, en definitiva es irreal, porque la propia estructura del relato es mucho más rígida y sistemática que la realidad (Rosenstone, 1997). Ese es precisamente el gran reto de la película histórica: la película deja de lado la complejidad de las causas de los hechos y, además, no tiene el rigor de los textos escritos, cerrando las puertas a otras opciones. A diferencia de la película, la realidad es abierta. El 
relato cinematográfico, por tanto, es cerrado, con punto de partida, desarrollo y final, y además, con orden y tiempo exactos. Por eso se contrapone al mundo real, en el que estos elementos estructurales son menos importantes (Gaudreault y Jost, 1995). Sin embargo, hay quien opina que la historia a través de las imágenes es mucho más compleja que el texto escrito, ya que incorpora más elementos: el cine tiene que reflejar todo lo sucedido en su conjunto, debe mostrar los zapatos, muebles, chaquetas, etc. de dicha época. Por eso tiene que interpretarlo e inventarlo (Martínez Gil, 2013).

\section{Una estructura muy concreta}

Mediante Silencio roto, Armendáriz ha intentado contar los sucesos de la posguerra española desde el punto de vista de los perdedores y de las mujeres y, más concretamente, desde la perspectiva de Lucía. El director aborda el tema del maquis a través de los intermediarios de la guerrilla. Así, en otoño de 1944, Lucía (Lucía Jiménez), de 21 años, regresa a un pueblo pirenaico huyendo de la capital española. Allí vivió en su infancia, antes de irse con su madre a Madrid; su padre fue asesinado durante la guerra por los franquistas.

\subsection{El viaje de Lucía}

El director ha basado el argumento en una estructura cinematográfica concreta: Lucía no sólo protagoniza el largometraje, sino que, además, la película utiliza la focalización interna a través de este personaje; es decir, el espectador recibe toda la información junto a Lucía. La focalización representa el grado de restricción de la información que la voz narrativa toma sobre las acciones de los personajes. En la narración, estas acciones siempre se presentan desde un ángulo determinado. En este caso, el punto de vista del narrador está dentro del héroe. El espectador y el personaje siempre saben lo mismo, por lo que los hechos se cuentan desde la experiencia de este personaje. Por eso no hay una escena en la que no aparezca. Esta decisión de Armendáriz a veces hace que la presencia de Lucía sea muy forzada: ella debe estar necesariamente en todas las escenas o pasajes de la historia, porque todo lo que recibe el espectador es lo que Lucía ve y escucha, convirtiendo sus observaciones en las del espectador. Sin Lucía no hay nada. Es por ello que dicho personaje fílmico requiere una atención especial. 
Este tipo de itinerarios presenta algunas características especiales. La primera, el choque frontal entre el mundo tradicional y el extraño. Campbell detalla que el neófito puede iniciar la aventura de muchas maneras inesperadas y, en este caso, Lucía inicia su aventura al volver al pueblo separándose de la protección maternal. Aunque no se vea en el largometraje, implícitamente se da a entender que el mundo ordinario de la protagonista es la ciudad y, en cambio, el pueblo pirenaico es el mundo extraordinario. Ese mundo ordinario es el punto de partida para la comparación. Mientras que en el mundo tradicional no hay guerra ("cinco años de paz y tranquilidad”), en el extraordinario se mantiene la confrontación bélica donde el maquis sigue en resistencia. Por eso, cuando Manuel (Juan Diego Botto) reconoce que su padre está en el monte desde hace tiempo, Lucía no entiende nada: “¿Todavía queda gente en el monte?... ¿Y qué hacen?”. Surge un conflicto entre estos dos mundos de difícil asimilación, por lo que al principio a la protagonista le resulta arduo creer en esa otra realidad:

Lucía: Pero si la guerra terminó hace años...

Teresa: Hay guerras y guerras hija, y algunas no terminan nunca, como esta.

Lucía: No diga tonterías tía. ¿Es que no escucha la radio? Se hartan de repetir que ya llevamos cinco años de paz y de tranquilidad.

A través de los hechos la protagonista se da cuenta de que la realidad es diferente, de que la guerra no ha terminado, de que los "cinco años de paz y tranquilidad", que tanto dice la radio, es mentira. Pero se trata de un conflicto ya planteado en el mundo ordinario que sólo hacía falta activarlo.

Para distinguir el mundo ordinario de lo insólito, siempre existe una frontera física y/o simbólica entre ambos, que el neófito debe atravesar. En este caso, se indica claramente cuál es el primer umbral: un camino estrecho con forma de puerta a la entrada del pueblo. Al principio de la película, Lucía viene del mundo tradicional al mundo inusual (F1) en autobús, y al final, Lucía deja definitivamente el mundo extraordinario para volver a lo habitual (F2). Es decir, cuando la protagonista aun es inmadura entra al mundo extraordinario. Es en ese mundo insólito donde desarrolla el proceso de madurez y, cuando definitivamente madura, sale para volver a la ciudad, al mundo ordinario 
completamente transformada. En este sentido, se trata de un tiempo cíclico 5 ya que el final es el espejo del inicio.

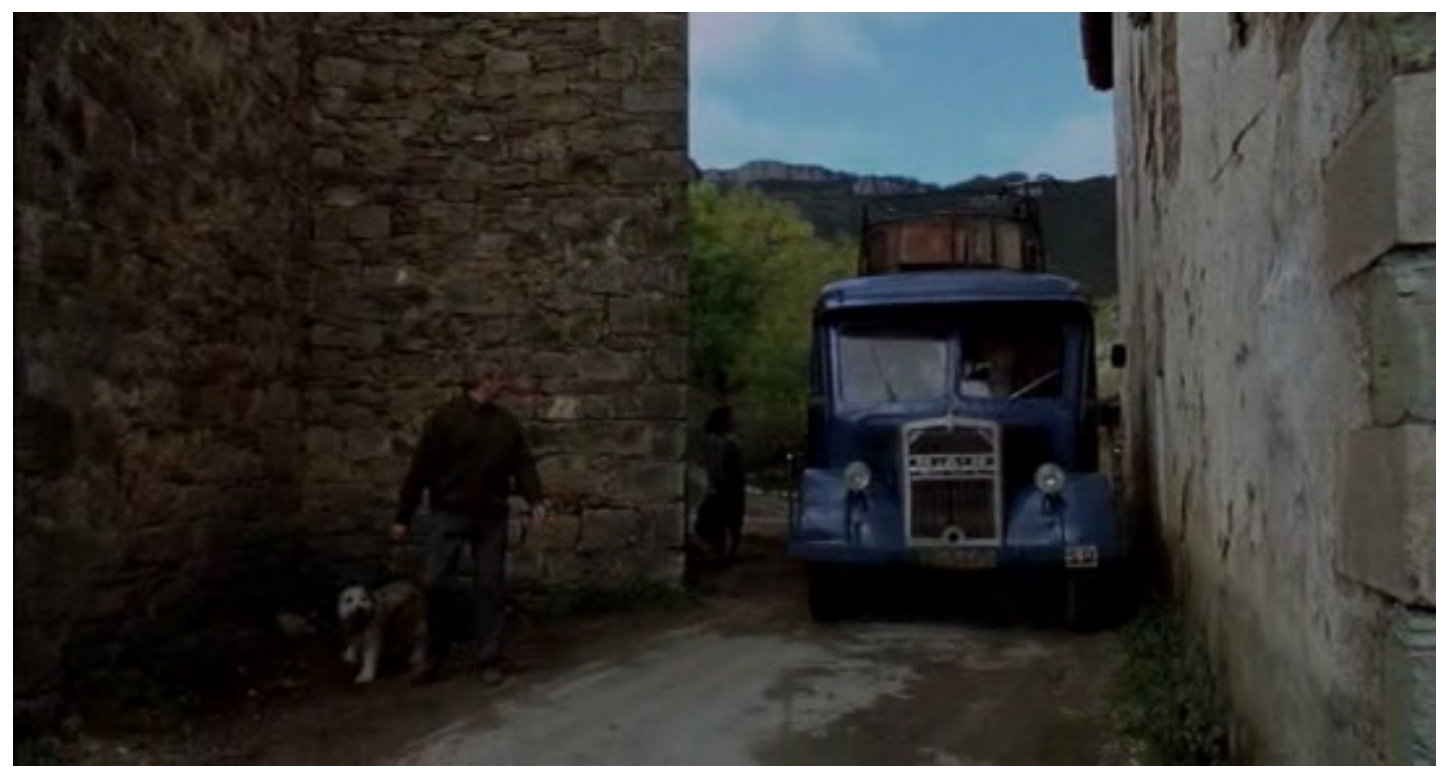

F1. Lucía en el autobús adentrándose en el mundo insólito.

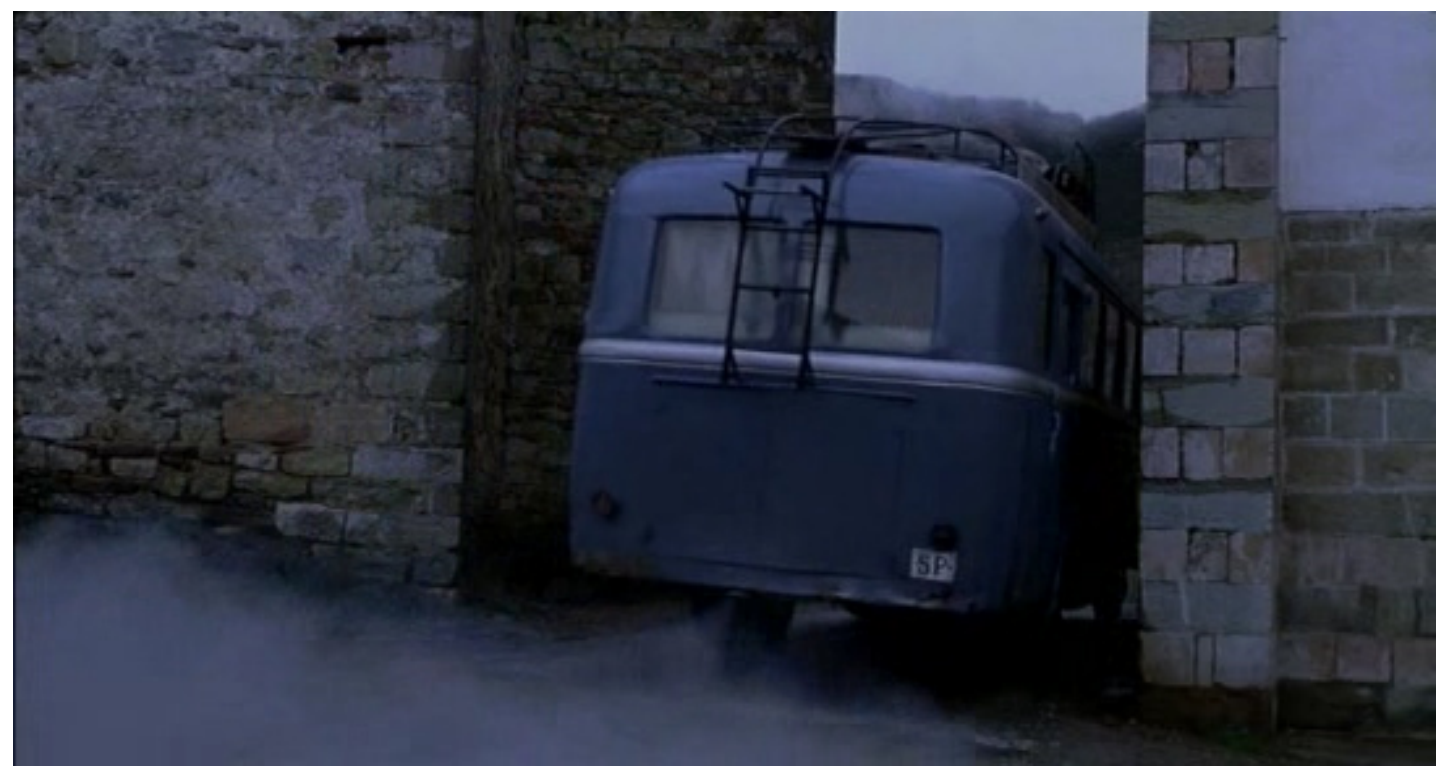

F2. Una vez terminado el proceso de madurez, Lucía sale en autobús del mundo insólito para volver al mundo ordinario.

Pero el héroe se encuentra con umbrales cada vez más difíciles de atravesar. Son obstáculos en el camino de la hazaña, son accesos a lo desconocido. Por eso es habitual que los defiendan poderosos guardianes. Lucía se percata de esa realidad

5 Casetti y Di Chio definen el tiempo cíclico como "aquel que está determinado por una sucesión de acontecimientos ordenados de tal modo que el punto de llegada de la serie resulte ser análogo al de origen, aunque no idéntico" (1991, p. 152). 
desconocida atravesando el umbral de la entrada al pueblo, pero no es el único umbral importante que cruza la protagonista: traspasando el umbral del bosque, Lucía conoce a la guerrilla. En el camino se encuentra con los guardianes que prohíben el acceso a lo desconocido: dos guardias civiles vestidos como "los del monte" que vigilan la arboleda en busca de maquis y/o enlaces (F3). Aunque constituyen una amenaza para la protagonista, consigue sortearlos.

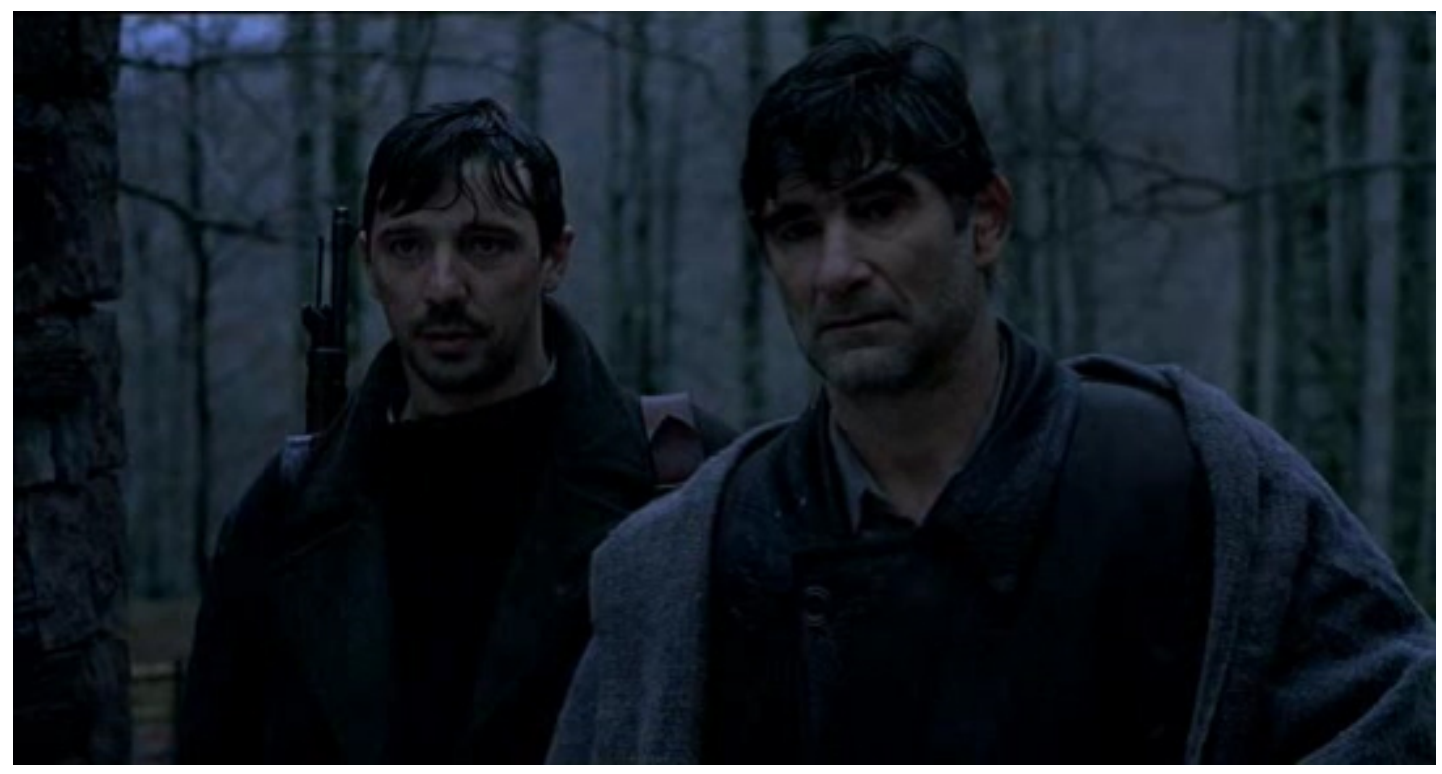

F3. Los guardianes que obstaculizan a Lucía el acceso a lo desconocido.

Este tipo de historias se enfrentan siempre a una dificultad: cómo expresar el proceso interno del personaje mediante la expresión externa, es decir, cómo explicar el proceso psicológico a través de la cámara. Este es un reto técnico en el que un movimiento interno -psicológico- debe ser representado mediante un movimiento externo. En este sentido, la película comienza con un autobús que atraviesa el umbral de la entrada al pueblo de izquierda a derecha y, finaliza con el autobús en el mismo punto, pero a la inversa, de derecha a izquierda. Ahora bien, entre estos dos autobuses la protagonista está en continuo movimiento: es muy habitual que Lucía se desplace de un lado a otro sobre la bicicleta a lo largo de toda la película. De este modo, el espectador puede ver a la chica ir del pueblo al monte y viceversa ( $\mathrm{F}_{4}$ y $\mathrm{F}_{5}$ ). La película consta de tres partes, y en las tres se puede apreciar a la protagonista moviéndose en bicicleta. Por si hubiera alguna duda, el director muestra con un plano detalle el movimiento del pedal y el plato de la bicicleta (F6). Todo ese movimiento físico representa el desplazamiento interno de Lucía. 


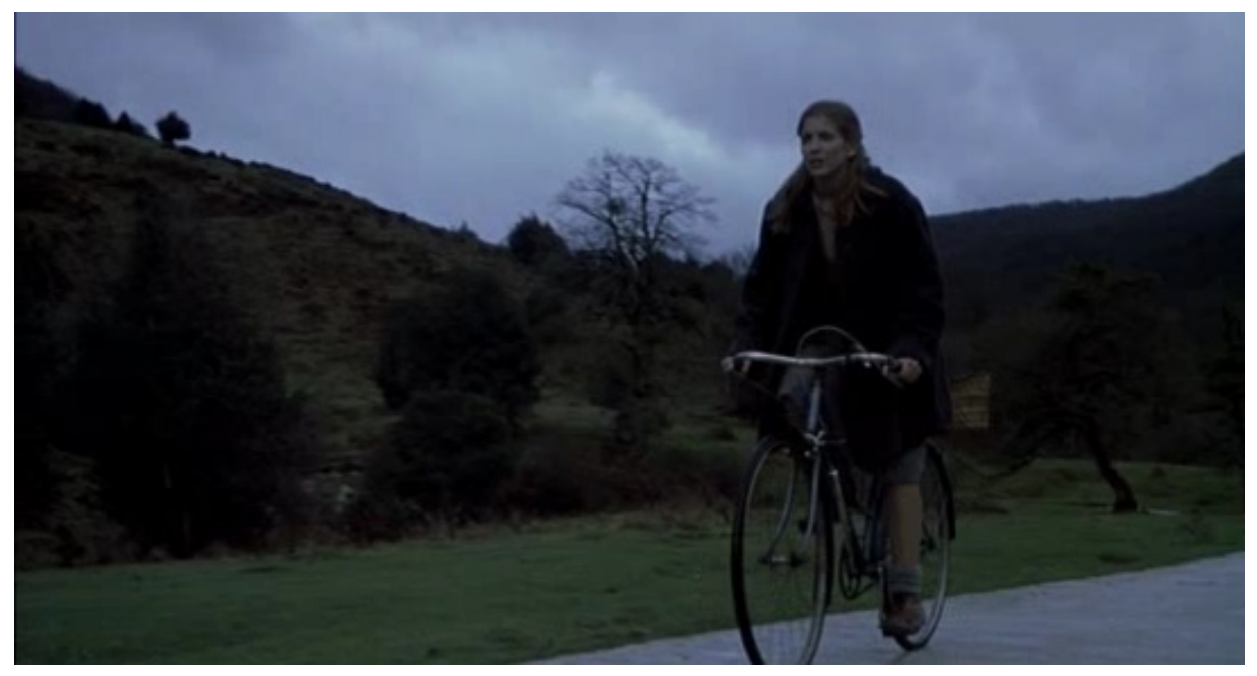

F4. Lucía volviendo al pueblo en bicicleta.

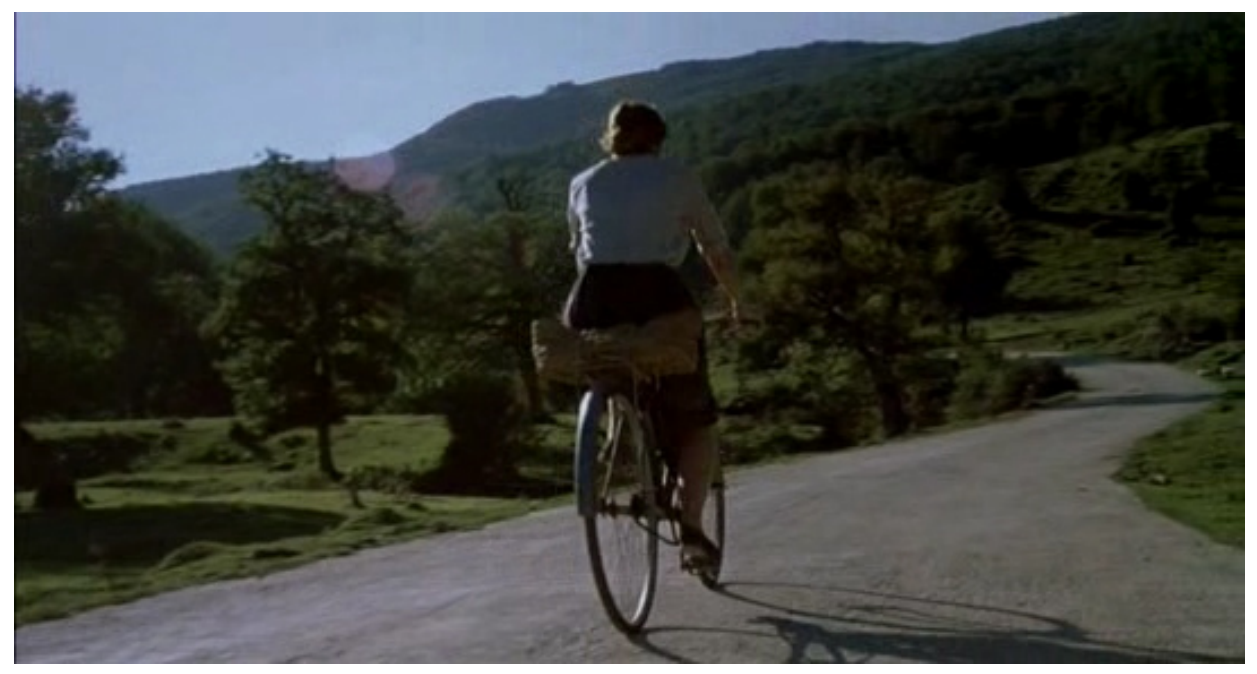

F5. Lucía se dirige al monte en bicicleta.

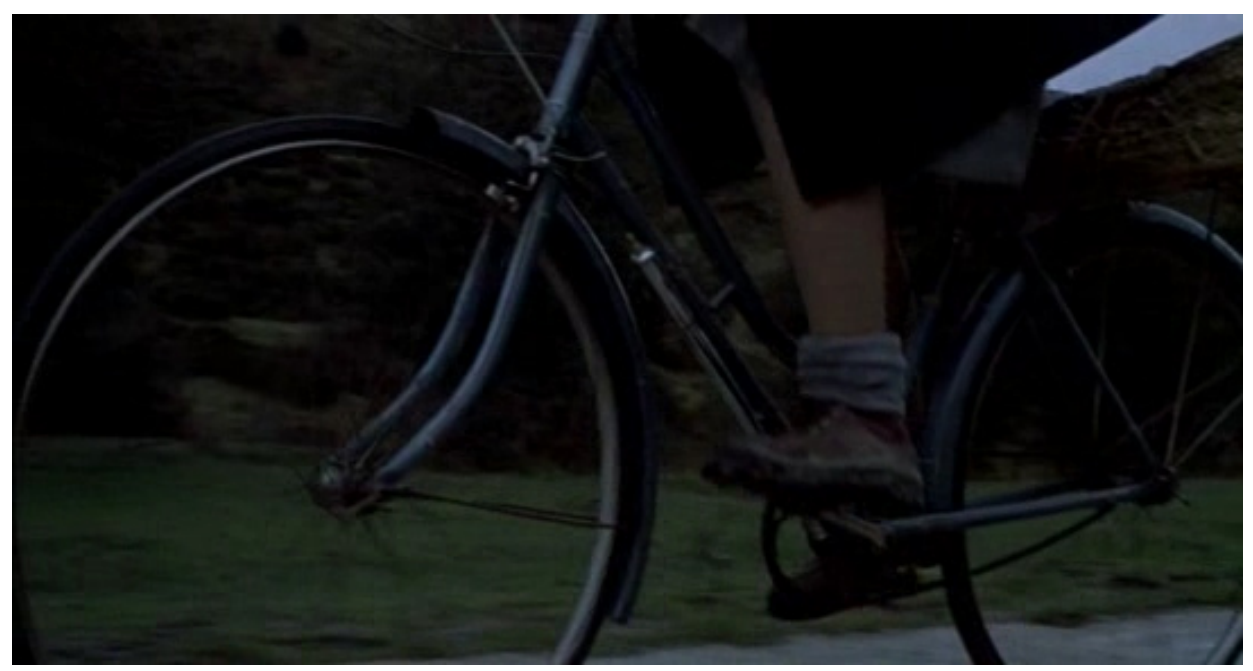

F6. Plano detalle de los pedales de Lucía. Mediante ese movimiento externo se simboliza el movimiento interno de la protagonista. 


\subsection{El mentor}

El neófito necesita un mentor que le aclare el camino en el proceso de madurez. El papel del guía es ofrecer al protagonista una lección de madurez. Este arquetipo suele ser un personaje que enseña y protege al héroe. Además de mentor, también se le llama intermediario, porque está entre dos mundos. En Silencio roto el mentor de Lucía es su tía. Teresa (Mercedes Sampietro) se encuentra entre estos dos mundos: está casada con un fascista, pero a la vez ayuda a los maquis. Encima, mantiene una relación especial con el republicano don Hilario (Álvaro de Luna). En la tercera parte del largometraje, Teresa esconde en su casa al fugitivo don Hilario aprovechando la estrecha relación de su marido con la Guardia Civil.

La instrucción es la función esencial del mentor. En este sentido, Teresa no tarda mucho en dar la primordial lección a su sobrina: “[...] No te fíes nunca de nadie, Lucía, de nadie. Sólo de lo que sientas aquí [el corazón] adentro. Fíate solo de eso". Teresa nunca se comporta de forma fingida, porque deja claro que no está a favor de nadie y que los ideales son sólo para los que viven de ellos, ella sólo sigue su corazón. Por tanto, aprovechando la buena relación de Cosme (Pepo Oliva) con los guardias civiles, ayuda a los disidentes del régimen. Pero no ofrece ayuda a cualquier disidente, sino al que ama. Es sobre todo un apoyo personal, no político. Y es exactamente lo que Lucía hace; ayuda a los maquis siguiendo a su corazón: Miguel.

En cuanto a no fiarse de nadie, los chivatos, las denuncias y las consecuencias son la piedra triangular de la película. Al principio del audiovisual, Alfredo (Gonzalo Baz), hijo del secretario, denuncia a Manuel y le obliga a huir al monte. Así, el director presenta la figura del denunciante, muy habitual en aquella época. Cualquiera puede ser el chivato, transmitiendo al espectador la sensación de desprotección. Más adelante, la información que Alfredo facilita en la plaza del pueblo al teniente (Joseba Apaolaza) provoca el suicidio de Rosario (Alicia Sánchez) hastiada por las torturas sufridas, y al mismo tiempo, el atentado en contra del delator.

El director mantiene esa veracidad hasta el final. En la tercera parte de la película, la última vez que Lucía sube a casa de Genaro (Joan Dalmau), se encuentra en el 
camino con guardias civiles que parecen maquis. Entonces, Juana (Asunción Balaguer) reconoce que no puede confiar en nadie: «Pues sí. Ahora los guardias se disfrazan como los del monte. Ya no te puedes fiar de nadie. Ni de los conocidos». Y ese es el final de la película: una conocida denuncia a Teresa y a don Hilario. A pesar de no aclararlo, todos los indicios apuntan a que Lola (María Botto) ha denunciado a sus amigos.

Básicamente, Teresa dirige al espectador la reflexión que cada uno debe realizar a través de Lucía. De esa manera vemos cómo este personaje induce diversas reflexiones al héroe que, en realidad, está trasladando a la audiencia. Por ejemplo, ella se muestra contraria a cerrar las viejas heridas por no generar más sufrimiento. Matías (Helio Pedregal), por su parte, apuesta por cerrar las heridas para mirar al futuro, en este caso ejecutando a Cosme, donde también se plantea al espectador una nueva reflexión. Pero, ¿quién se atreve a curar las viejas heridas? Ese es el desafío que lanza Teresa, un nudo gordiano que la sociedad sigue sin resolver. La pregunta queda sin respuesta.

\subsection{Los ayudantes}

Además del mentor, el héroe también dispone de acompañantes. En este caso, los ayudantes de Lucía son don Hilario y Manuel. Estos dos personajes no son tan decisivos como Teresa, pero de una manera $\mathrm{u}$ otra ayudan a la protagonista a madurar. Don Hilario ayuda a Lucía a reflexionar sobre la esperanza que plantea la película. Esperanza es el mensaje que prevalece en Silencio roto: a su modo, todos los protagonistas exponen dicho mensaje. El ex maestro tiene como misión ilusionar la resistencia, mantener la esperanza de quienes luchan por liberarse de las garras franquistas y, para ello, recurre continuamente a los ideales de paridad. Más tarde, Lucía le confiesa que está cansada de los guerrilleros, y él le contesta que las personas pueden equivocarse, pero lo importante son las ideas que se defienden. El camino puede ser a veces incierto, pero lo fundamental es la idea. Por lo tanto, don Hilario se mueve en dos ejes: por un lado, genera esperanza y, por otro, es la expresión del idealismo. Las dudas que puede tener Lucía para alejarse de la resistencia antifranquista son resueltas por un ideólogo, don Hilario, primer ayudante del neófito. La función de este personaje fílmico es la instrucción política del héroe. 
El segundo ayudante, Manuel, apunta hacia el mismo camino: «Cometemos errores, pero hay que seguir». Pero, a diferencia del anterior, el cometido de este personaje no es la instrucción ideológica, sino la expresión de una participación activa: para hacer frente a la injusticia hay que hacer algo; no se pueden dejar las cosas como están. Si Teresa es sentimiento y don Hilario es conciencia, este personaje fílmico es pura acción. Sin embargo, no participa a ciegas, sino que reflexiona en profundidad sobre la idoneidad de la resistencia antifranquista. En una importante conversación con Lucía, ella duda de si merece la pena tantas muertes. Dentro de la espiral de "acción-reacción" que se llevaba a cabo en aquella época, la violencia de cada bando no sólo acusaba al enemigo, sino también a familiares y allegados, más aún en el caso de la resistencia. Manuel no es ideólogo, no tiene respuesta. A partir de ahí, Manuel pone sobre la mesa otra reflexión: "Nuestra causa es justa, ¿no?”. Lucía indica que la causa lo es, pero vacila en cuanto a los procedimientos. Armendáriz mantiene la duda abierta.

Por último, cuando el neófito llega a la madurez, ya no es necesario el mentor ni los acompañantes. A menudo, para expresar esa madurez se manifiesta a través de la muerte del mentor. Por eso, al final de la película, los tres guías de Lucía son asesinados de continuo. Lucía no necesita saber más porque ha aprendido el sentimiento (Teresa), la esperanza (don Hilario) y la importancia de la participación (Manuel). Y, por tanto, cuando la protagonista llega a la madurez política, moral y sentimental, deja el mundo extraordinario atravesando el umbral del pueblo en dirección contraria y vuelve al mundo tradicional, esta vez, totalmente transformada. Lucía vuelve sensata a la ciudad. No es casualidad que ella asuma la función desempeñada por don Hilario hasta entonces: generar esperanza. Ella seguirá enviándole a Genaro las cartas del hijo fallecido en la guerra.

Por lo tanto, se trata de una historia circular. Uno muere para que la otra continúe. Esa idea, intensificada por la propia circularidad de las estaciones, se puede apreciar también en el nacimiento de la hija de Lucía. Ese es, precisamente, el vínculo elemental para que la protagonista, esta vez con la lección aprendida, vuelva al mundo ordinario e instruir así a la recién nacida. La hija es el futuro y, por ello, Lucía deposita la foto de la hija en el lugar donde yace enterrada la abuela (F7). Armendáriz muestra unidos un pasado desesperado -Rocío se ahorcó- con 
un futuro esperanzador -las ganas de vivir de una recién nacida-. Esa esperanza por el futuro se acentúa con la muestra del arcoíris en el momento en que Lucía se marcha definitivamente del pueblo. Después del oscuro invierno llega la primavera. La única estación que el film no muestra pero que da a entender.

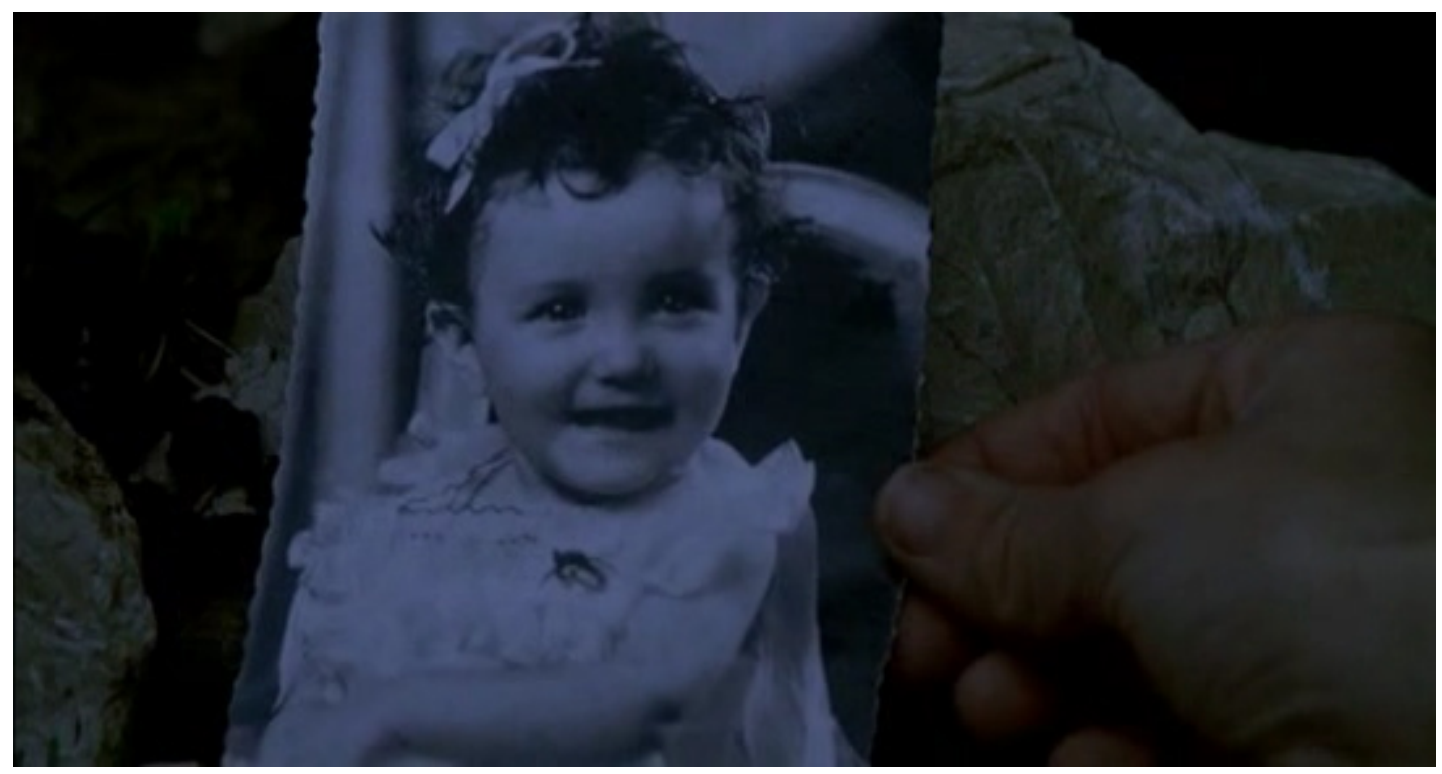

F7. Fotografía de la hija de Lucía sobre la tumba de la abuela.

\subsection{La fuerza que desafía al héroe}

La película presenta tres etapas concretas, muy destacadas y muy diferentes: el otoño de 1944, el verano de 1946 y el invierno de 1948. En la primera época se presenta la resistencia antifranquista; en la segunda, la ilusión y la esperanza predominan cuando los guerrilleros bajan del monte y toman el pueblo; y en la tercera, los personajes principales están completamente desesperados. En la segunda parte del film, entra en escena una fuerza nueva que desafía al héroe: el teniente. El mando de la Guardia Civil llega con el objetivo de restablecer el régimen franquista en el pueblo controlado por los rebeldes. Silencio roto tiene una estructura totalmente simétrica y en la parte central de la película [00:54:20] hay un suceso que la divide en dos: cuando el teniente ejecuta a quemarropa delante de todo el pueblo a un maquis que se había entregado, al mismo tiempo que ordena el fusilamiento de su mujer. Ese es precisamente el primer asesinato que se aprecia directamente. Hasta entonces, la película va por la senda de la esperanza, pero a partir de ese punto se va imponiendo la desesperación. Por lo tanto, el teniente anuncia la llegada de un cambio significativo; él es el heraldo. 
El cometido de este personaje fílmico es alterar el equilibrio del neófito; desde su aparición, nada es igual. En consecuencia, Lucía debe tomar decisiones que antes nunca se había planteado. Esta figura es esencial para el desarrollo de la protagonista.

\section{Conclusiones}

La prueba definitiva para saber si una historia ha sido exitosa es la reputación y la influencia positiva por parte de los espectadores. Dada cuenta del éxito taquillero de Silencio roto y su repercusión en la comunidad científica, Armendáriz ha acertado con la estructura narrativa empleada.

Silencio roto plantea una serie de reflexiones a lo largo del film que son el reflejo del proceso vivido por la izquierda española desde la guerra hasta la Transición, es decir, el director critica la forma de la lucha, no en el contenido. Por consiguiente, la estructura narrativa escogida es ideal para el mensaje que pretende trasladar. Mediante la focalización interna, vemos cómo Lucía recibe junto al espectador un proceso de madurez política, moral y sentimental según lo que ve y escucha. Al final del film, el espectador, al igual que Lucía, adquiere una sabiduría antes no poseída. En consecuencia, el enfoque elegido por el director es idóneo para transmitir la evolución que desea mostrar, ya que este tipo de focalización ayuda a identificar al espectador. Armendáriz emplaza al espectador a depositar su confianza en el héroe mientras dura la aventura. Cómo Vogler afirma, «nos convertimos en héroes por un rato» (2002, p. 66).

Así mismo, podemos afirmar que las pautas proporcionadas en El viaje del héroe siguen vigentes en el cine contemporáneo. Son estructuras narrativas que funcionaron, funcionan y seguirán funcionando. Eso no significa que la adaptación de una historia a dicha estructura narrativa conlleve siempre el éxito. En ese sentido, sería erróneo forzar una historia para que encaje en patrones preestablecidos concretos. Armendáriz se ha tomado ciertas libertades a la hora de desarrollar el relato: no ha seguido al pie de la letra los patrones establecidos, sino que ha ido estructurando la historia según sus necesidades. Un claro ejemplo es que Silencio roto no nos muestra el mundo ordinario del héroe, sino que nos lo presenta implícitamente. La llamada a la aventura se da prácticamente desde el inicio. 
El estudio llevado a cabo manifiesta que los aspectos formales de una película son igual de importantes que su historia. Por lo tanto, es un viso que no se debe obviar tanto a la hora de realizar un film, como en el momento de analizarlo.

\section{Referencias bibliográficas}

Aguilar Carrasco, P. (2010). El análisis audiovisual: un puente entre los valores pensados y los valores sentidos. Tabanque Revista pedagógica, núm. 23, 69-82.

Campbell, J. (1990). El héroe de las mil caras: psicoanálisis del mito (trad. Hernández, J. F.). México DF: Fondo de Cultura Económica. (Original publicado en 1949).

Casetti, F. y Di Chio, F. (1991). Cómo analizar un film. Barcelona: Paidós.

Cervera C. y Cabanelas L. M., "Los 18 errores históricos de Mientras dure la guerra, la película sobre Franco y Unamuno de Amenábar", $A B C, 29$ de octubre de 2019 [consultado el 18 de noviembre de 2019].

García Landa, J. A. (1998). Acción, relato, discurso. Estructura de la ficción narrativa. Salamanca: Ediciones Universidad de Salamanca.

Gaudrealult, A. y Jost, F. (1995). El relato cinematográfico. Cine y narratología. Barcelona: Paidós Ibérica.

Henderson, M. (2005). Star Wars: La magia del mito. Barcelona: Círculo Latino.

Martínez Gil, F. (2013). La historia y el cine: ¿unas amistades peligrosas? Vínculos de Historia, núm. 2, 351-372.

Marzabal, I. (2004). Deliberaciones poéticas. Cine y ética narrativa. Bilbao: Servicio editorial de la Universidad del País Vasco/Euskal Herriko Unibertsitatea.

Pampín A. G. (2015). El viaje turístico como viaje sagrado: análisis de experiencias turísticas desde la mitología y función psicológica del mito. Anais Brasileiros de Estudos Turísticos, vol. 5, núm. 1, 8-21.

Pérez Rufí, J. P. (2016). Metodología de análisis del personaje cinematográfico: Una propuesta desde la narrativa fílmica. Razón y palabra, núm. 95, 534552.

Rosenstone, Robert A. (1997). El pasado en imágenes. El desafío del cine a nuestra idea de la historia. Barcelona: Ariel Historia.

Seger, L. (1994). Cómo convertir un buen guion en un guion excelente. Madrid: Rialp.

Vogler, C. (2002). El viaje del escritor. Las estructuras míticas para escritores, guionistas, dramaturgos y novelistas. Barcelona: Ediciones Robinbook. 